\title{
Rancang Bangun Antena Dual Band Menggunakan Aplikasi 4nec2 Untuk Komunikasi Melalui Satelit Amatir
}

\author{
Faisal Rizkan $^{1}$, Moethia Faridha ${ }^{2}$ \\ Program Studi Teknik Elektro, Universitas Islam Kalimantan MAB ${ }^{12}$ \\ faisalrizkan@gmail.com.bariethia@gmail.com
}

\begin{abstract}
Abstrak - Satelit Amatir telah banyak digunakan para amatir radio di seluruh dunia untuk media berkomunikasi. Satelit ini juga sangat berperan penting dalam penanggulangan bencana di saat mode komunikasi lain tidak lagi dapat diandalkan. Satelit amatir pada umumnya memiliki Voice Repeater yang dapat digunakan untuk menerima sinyal suara yang dikirim dari bumi dan pacarkan kembali secara luas dengan frekuensi dan band yang berbeda. Untuk dapat berkomunikasi melalui Voice Repeater, diperlukan antena yang mampu mengarahkan seluruh daya dari pemancar agar sinyalnya mampu mencapai satelit yang mengorbit di ketinggian sekitar 650 kilometer dan antena juga harus sensitif untuk menerima sinyal downlink dari satelit.
\end{abstract}

Skripsi ini membahas mengenai perancangan dan pembangunan sebuah antenna dual band pada frekuensi $145.880 \mathrm{MHz}$ dan $435.880 \mathrm{Mhz}$ yang akan digunakan untuk berkomunikasi pada Voice Repeater satelit Lapan A2 dengan dibantu aplikasi perancangan antena bernama 4NEC2. Bahan pembuat antenna yang dipakai adalah aluminium tabung dengan diameter $8 \mathrm{~mm}$ yang banyak dijual dipasaran.

Dari hasil pengukuran antenna yang telah dibangun, didapatkan selisih frekuensi kerja serta gain dibandingkan dengan simulasi pada 4NEC2. Frekuensi kerja hasil pengukuran adalah 148.052 $\mathrm{MHz}$ dan 442.667MHz dengan gain 6.71 $\mathrm{dBi}$ sedangkan frekuensi kerja pada
4NEC2 adalah $145.880 \mathrm{MHz}$ dan 435.880 MHz dengan gain 9.33dBi.

Kata Kunci : Satelit Amatir, Amateur Sattelite, Amsat, Antena, Dual Band, 4 nec2

\section{PENDAHULUAN}

Untuk dapat berkomunikasi melalui voice repeater pada satelit amatir, diperlukan antena yang mampu mengarahkan seluruh daya dari pemancar agar sinyalnya mampu mencapai satelit yang mengorbit di ketinggian sekitar 650 kilometer.

Dalam penelitian ini penulis terlebih dahulu melakukan penelitian dan pembandingan terhadap dua antena yang menurut penulis paling mudah dirancang dan paling mudah dibangun menggunakan aplikasi 4NEC2, yaitu 7 elemen dual band moxon yagi dan 9 elemen dual band yagi. Hasil simulasi kedua antena tersebut akan dibandingkan dan hasil desain dengan parameter terbaik kemudian direalisasikan dan diukur parameterparameternya sesuai standar pengukuran antena IEEE Std 149-1979 seta dilakukan pengujian fungsi apakah antena tersebut dapat digunakan untuk berkomunikasi melalui satelit amatir.

$$
\text { Rumusan masalah dalam }
$$

penelitian ini adalah bagaimana cara 
menemukan desain dan ukuran terbaik dari kedua antena dual band moxon dan yagi dan cara membandingkannya, serta bagaimana menganalisa kualitas antena sesuai standar pengukuran antena pada IEEE std 149-1979.

\section{METODE PENELITIAN}

A. Tahapan Perancangan Antena

1. Lokasi Penelitian : Balai Monitor Spektrum Frekuensi Radio Palangkaraya

2. Studi Literatur mengenai antena dual band moxon yagi 7 elemen dan antena dual band yagi 9 elemen.

3. Melakukan simulasi perancangan pada aplikasi 4NEC2 untuk desain antena dual band moxon yagi 7 elemen dan antena dual band yagi 9 elemen.

4. Melakukan optimasi pada setiap desain antena hingga ditemukan parameter terbaik dengan target Weighting Factors $100 \%$ pada SWR dan $100 \%$ pada Gain.

B. Tahapan Pembangunan Antena

1. Hasil desain pada 4NEC direalisasikan menggunakan bahan pipa aluminium berdiameter $8 \mathrm{~mm}$ dan ketebalan $1 \mathrm{~mm}$.

2. Boom atau tongkat poros penahan elemen antena terbuat dari aluminium profil kotak $2 \times 2 \mathrm{~cm}$ agar mudah menempatkan elemen diatasnya serara lurus dan rapi.

Dari hasil perhitungan optimizer 4NEC2 atas kedua rancangan yang telah dilakukan, dapat dilihat pada tabel 1:

Tabel 1 Perbandingan parameter antara rancangan antena Moxon-Yagi 7 elemen dan Yagi 9 elemen

\begin{tabular}{|c|c|c|c|c|c|}
\hline \multirow[b]{2}{*}{ PARAMIEIER } & \multicolumn{2}{|c|}{$\begin{array}{l}\text { MOXON-YAGI } \\
7 \text { ELEMEN }\end{array}$} & \multicolumn{2}{|c|}{$\begin{array}{c}\text { YAGL } \\
\text { P H.FMEN }\end{array}$} & \multirow[b]{2}{*}{ KETERANGAN } \\
\hline & $\begin{array}{l}145.850 \\
\mathrm{MHz}\end{array}$ & $\begin{array}{l}435 \mathrm{ESO} \\
\mathrm{MHz}\end{array}$ & $\begin{array}{l}1+5.550 \\
\mathrm{MHz}\end{array}$ & $\begin{array}{l}455880 \\
\mathrm{MHz}\end{array}$ & \\
\hline GALN (dBi) & 6,25 & 10,45 & 933 & 9,85 & $\begin{array}{l}\text { Yagi } 9 \text { Element } \\
\text { lethih raggual } \\
\text { pada fekuiensi } \\
145.580\end{array}$ \\
\hline 5WR & 101 & 1.01 & 1.00 & 1,026 & 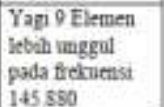 \\
\hline $\begin{array}{l}\text { RETURS } \\
\text { LOSS }\end{array}$ & -44.35 & -44.35 & -49.62 & $-37,69$ & $\begin{array}{l}\text { Yagi 9 Elemen } \\
\text { lebah unggul } \\
\text { pada frekuensi } \\
145.590\end{array}$ \\
\hline
\end{tabular}

Dari hasil perbandingan tersebut, penulis mengambil desain antena yagi dual band 9 elemen untuk direalisasikan dan dilakukan pengukuran hingga mendapatkan hasil sebagai berikut:

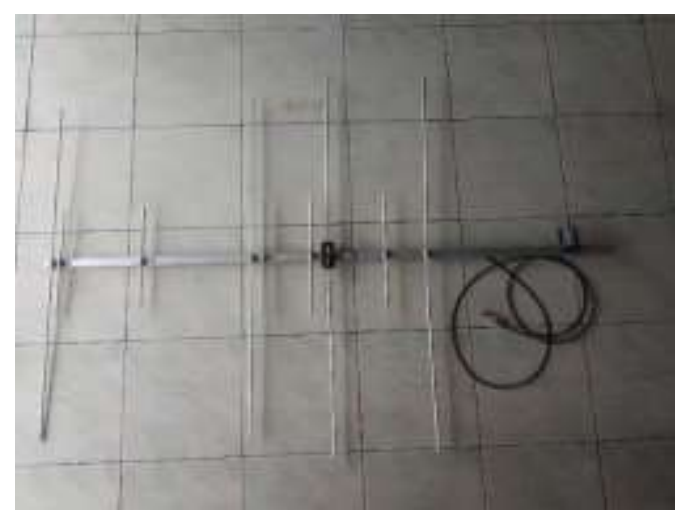

Gambar 1 Realisasi antena dual band Yagi 9 elemen

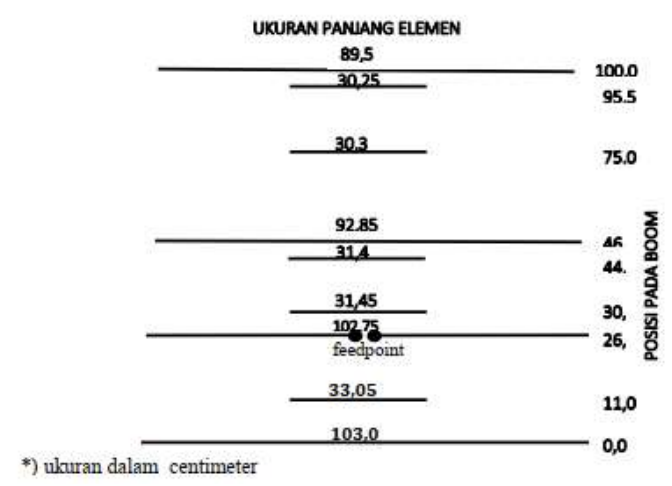

Gambar 2 Ukuran antena dual band Yagi 9 elemen 


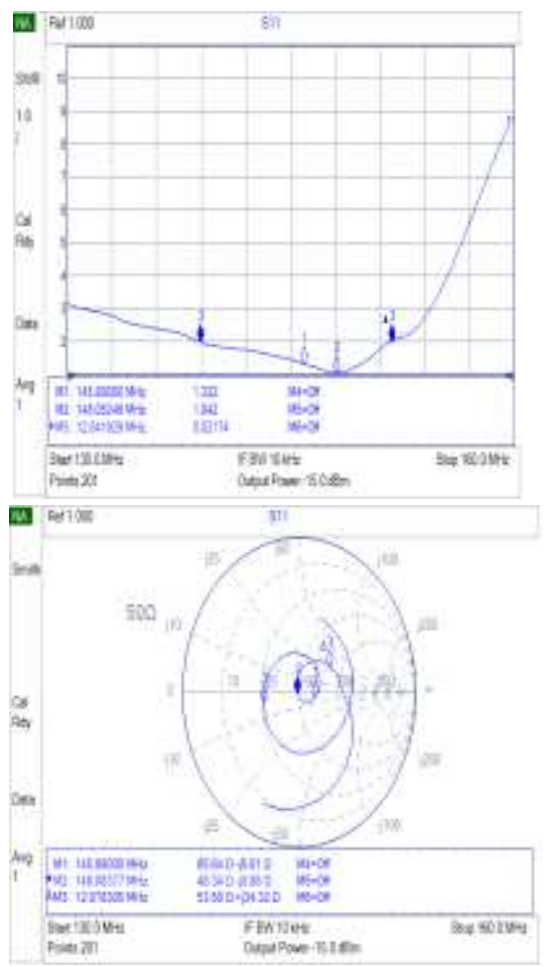

Gambar 3 Hasil pengukuran VSWR dan impedansi masukan di $2 \mathrm{M}$ band
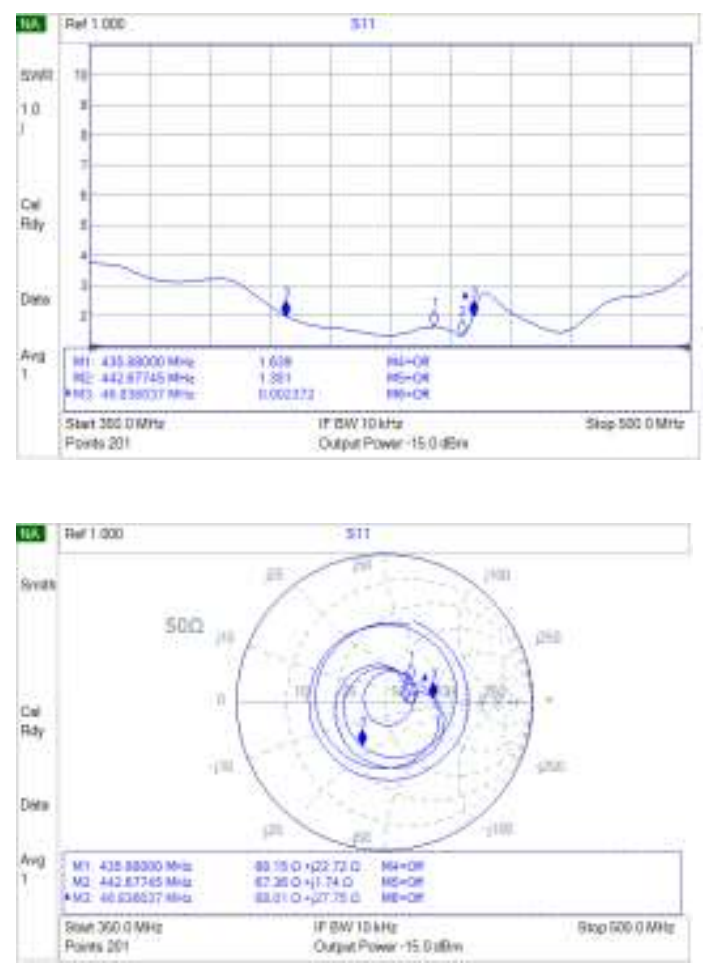

Gambar 4 Hasil pengukuran VSWR dan impedansi masukan di $70 \mathrm{~cm}$ band

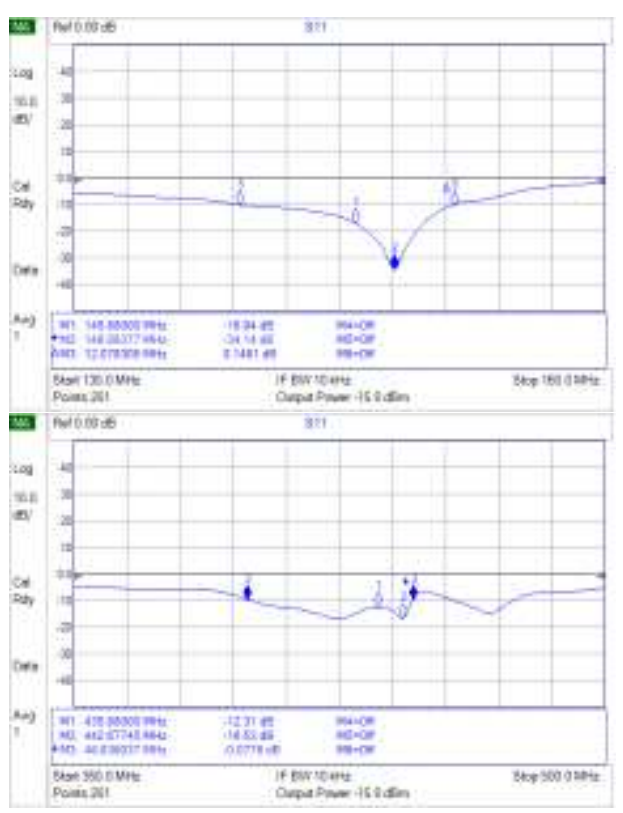

Gambar 5. Hasil pengukuran return loss di $2 \mathrm{M}$ band dan $70 \mathrm{~cm}$ Band

Tabel 2 Hasil pengukuran parameter S11 antena dual band yagi 9 elemen

\begin{tabular}{|c|c|c|c|}
\hline \multirow[b]{2}{*}{ PARALEER } & \multicolumn{2}{|c|}{ FREXUENI } & \multirow[b]{2}{*}{ REEERAIGAS } \\
\hline & $\begin{array}{l}145.88 \\
\text { OUIHz }\end{array}$ & $\begin{array}{l}-35800 \\
132\end{array}$ & \\
\hline VSTR & 1332 & 1.639 & 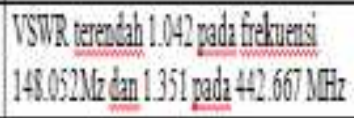 \\
\hline $\begin{array}{l}\text { Reinin loss } \\
\text { (iL) }\end{array}$ & -16.94 & 1231 & 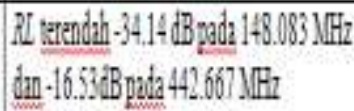 \\
\hline $\begin{array}{l}\text { Impedans } \\
\text { Varolten }\end{array}$ & $\begin{array}{l}65.640 \\
6 \\
6.019\end{array}$ & $\begin{array}{l}68110 \\
- \\
j 22720\end{array}$ & 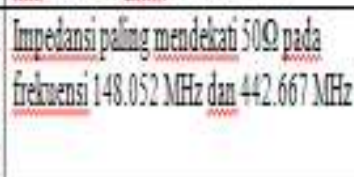 \\
\hline $\begin{array}{l}\text { Benowititi } \\
\text { Artane }\end{array}$ & $\begin{array}{l}12078 \\
\mathrm{~N} / \mathrm{Hz}\end{array}$ & $\begin{array}{l}46.836 \\
10 \mathrm{~Hz}\end{array}$ & 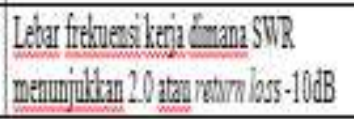 \\
\hline
\end{tabular}

Selanjutnya dilakukan pengukuran pola radiasi antena dan didapatkan hasil seperti pada gambar 6 : 
EEICT

https://ojs.uniska-bjm.ac.id/index.php/eeict
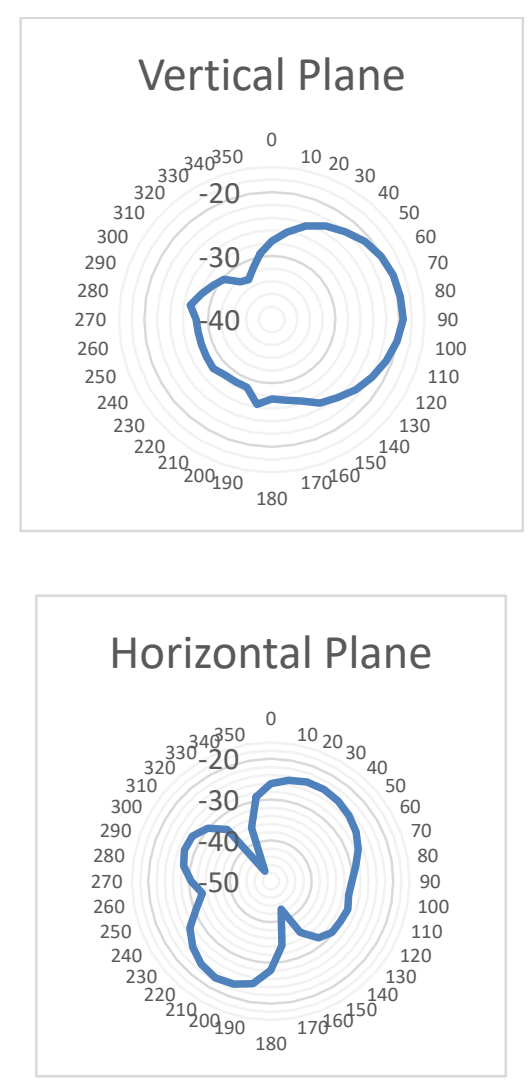

Gambar 6 Pola radiasi antena

Dengan menggunakan signal generator dan referensi antena dipole ETS Lidgren 3121D yang memiliki gain sebesar $1.5 \mathrm{dBi}$, terukur level daya $-19.04 \mathrm{dBm}$ sedangkan pada antena dual band yagi 9 elemen sebesar $-13.85 \mathrm{dBm}$, maka gain dapat dihitung dengan rumus sebagai berikut:

$$
\begin{aligned}
& G_{A U T}(d B i)=\left(P_{A U T}(d B m)-\right. \\
&\left.P_{\text {ref }}(d B m)\right)+G_{\text {ref }}(d B i) \\
&=(-13.85 \mathrm{dBm}- \\
&(-19.04 \mathrm{dBm}))+1.5 \mathrm{dBi} \\
&= 5.21 \mathrm{~dB}+1.5 \mathrm{dBi} \\
& G_{A U T}(d B i)=6.71 \mathrm{dBi}
\end{aligned}
$$

Jadi gain antena yagi dual band 9 elemen adalah sebesar $6.71 \mathrm{dBi}$.

Hasil pengujian fungsi antena terbukti dapat digunakan untuk berkomunikasi e - ISSN: $2615-2169$

p - ISSN: $2654-4296$

pada satelit amatir LAPAN A2 (IO-86) hanya dengan HT 5 watt.

\section{KESIMPULAN}

1. Berdasarkan perhitungan 4NEC2, Antena dual band yagi 9 elemen memiliki gain yang lebih besar dibanding antena dual band Moxon-yagi 7 elemen.

2. Antena dual band Yagi 9 elemen dengan bahan pipa aluminium berdiameter $8 \mathrm{~mm}$ dan ketebalan $1 \mathrm{~mm}$ memiliki gain terukur hingga $6.71 \mathrm{dBi}$ dan sudah teruji dapat berkomunikasi pada satelit amatir dengan kualitas pancaran sinyal yang bagus.

3. Perbedaan frekuensi kerja serta gain antena pada simulasi 4NEC2 dapat diakibatkan konduktivitas dan kemurnian bahan aluminium yang ada dipasaran tidak sama dengan standar aluminium yang digunakan pada aplikasi 4NEC2.

\section{DAFTAR PUSTAKA}

ARRL. (2019). Handbook For Radio Communications. The American Radio Relay League,Inc.

Balanis, C. A. (2005). Antenna Theory Analysis And Design Third Edition. A John wiley \& Sons, Inc., Publication.

BRIN. (2015, 09 28). Badan Riset dan Inovasi Nasional. Retrieved from https://www.ristekbrin.go.id/kaba r/open-236/

IEEE Std 149. (1979). IEEE Standard Test Procedures for Antennas. The Institute of Electrical and Electronics Engineers, Inc.

Schoonover, M. (2017). 4NEC2 The Definitive Guide. Leanpub. 